\title{
Customized Production Project Risk Management with Analytic Hierarchy Process
}

\author{
Junxin Zhong1,2, Jintai Lv ${ }^{1,3}$, Ying Zhang1,4 \\ ${ }^{1}$ School of Business Administration, South China University of Technology, Guangzhou, China \\ ${ }^{2}$ Engineering, Ji Neng Composite Material \& Products (Guangzhou) Ltd., Guangzhou, China \\ ${ }^{3}$ Service Center, Guangzhou Tianwei Information Technology Co. Ltd., Guangzhou, China \\ ${ }^{4}$ General Management, GRG Banking I.T. Co. Ltd., Guangzhou, China \\ Email: free623@126.com, lvjt@tiancom.com, zying10@grgbanking.com
}

How to cite this paper: Zhong, J.X., Lv, J.T. and Zhang, Y. (2019) Customized Production Project Risk Management with Analytic Hierarchy Process. Open Journal of Social Sciences, 7, 85-95.

https://doi.org/10.4236/jss.2019.71008

Received: December 20, 2018

Accepted: January 11, 2019

Published: January 14, 2019

Copyright $\odot 2019$ by author(s) and Scientific Research Publishing Inc. This work is licensed under the Creative Commons Attribution International License (CC BY 4.0).

http://creativecommons.org/licenses/by/4.0/

\begin{abstract}
Based on the PMBOK risk management frame, this paper collects the potential risk factors of the customized project of company $\mathrm{T}$ with Delphi method. After several rounds of research, we get 22 level three factors from the original 6 level one factor. Then we filtrate all the 22 level three factors to identify the TOP10 factors with Analytic Hierarchy Process (AHP). This method is qualitative and quantitative. The project manager can find out the critical factors quickly. It's very helpful to analyze and solve issues during project management.
\end{abstract}

\section{Keywords}

Customized Production Project, Risk Management, Research on Critical Factors, Analytic Hierarchy Process, Lean Production, Delphi Method

\section{Introduction}

As a brand new production mode, customized production aims to produce customized products under acceptable cost and time line. Enormous investment is also required for the new technology and equipments. The internal and external environment changes very quickly as well. The risk happens everywhere, which is believed that a valid risk management is very critical to the success of the project [1]. While the current risk management effect depends on the experience of the project manager. All the arrangements and decisions made under this situation are very subjective. Besides, it's very difficult to find out and focus on the most critical factors when all of them come to you in the same time. There is a big challenge to transfer the risk management knowledge to your peers as well. It 
is a big waste to the company.

This paper uses AHP to calculate the weight of each critical factor and rank them. It's quantitative and qualitative which can help avoid the subjective decisions. It's also very easy for the project managers to find out the important factors to help improve the efficiency of the project risk management. The project management knowledge with the AHP can be stored and transferred as well.

\section{Literature Review}

In the 1960s, risk management becomes a subject. The purpose of the traditional risk management is to decrease the negative effect to the business operation and sustainable development. The primary strategy is to avoid or transfer the risk [2] [3]. Insurance is the most important tool in this period. The risk management research focus on the credits risk and financial risk [4]. The Global Association of Risk Professionals (GARP) established in 1996. It drives the establishing and perfecting of the certification and qualification examination system. The GARP is accepted and recommended by the financial industry in many countries. It becomes the principle standard to measure the risk management ability of the employee. In the same year, Project Management Institute (PMI) issues the first edition of PMBOK. Risk management is one of the nine knowledge field and never been removed since that [5] [6]. Project risk is defined as an uncertain event or condition by $\mathrm{PMBOK}$ the $5^{\text {th }}$ edition. It will create positive effect or negative effect to the project objective once happened. The target of project risk management is to enhance the percentage and effect of the positive events and lower them on the negative events. The risk management is divided into six processes by $\mathrm{PMBOK}$ risk management frame. They are plan the risk management, identify the risk, implement qualitative risk analysis, implement quantitative risk analysis, plan the risk response and control the risk [7].

AHP (Analytic Hierarchy Process) is suggested by Professor T.L. Saaty from University of Pittsburgh in the early 1970s. It's an easy and flexible quantitative decision-making method to qualitative questions. It can divide various factors from complicated problems into different levels to make them more systematical [8].

According to the subjective judgment of the objective reality, the AHP combines the expert advice and analysis judgment effectively. First of all, make quantitative description of the importance between different factors in the same level. Then calculate each factor's weight of importance. At last, rank the factor based on the weight of importance. The AHP combines the qualitative and quantitative analysis, flexible and systematical to deal with different kinds of problems, which help it get widely attention and application quickly.

\section{Identify Risk Factors}

Based on the six processes of risk management in the PMBOK, we identify the critical factors of customized production projects with Delphi. In the first round 
open research, we identify the secondary factor from A1 plan the risk management、A3 implement qualitative risk analysis、A4 implement quantitative risk analysis、A5 plan the risk response and A6 control the risk. We get 11 secondary factors. In the second round evaluation research, we identify the secondary factor from A2 identify the risk and identify the third factor from 11 secondary factors in the meantime. It totally takes 3 rounds. We get 7 secondary factors and 22 third factors from original 6 primary factors. Establish the critical factor evaluation system of customized production project. See Table 1.

\section{Rank Risk Factors with AHP}

\subsection{AHP Procedure}

In order to find out the top 10 critical risk factors, this paper analysis all the 22 risk factors with AHP, below is the procedure:

1) Create hierarchy structure model

2) Construct comparison matrix

Table 1. Critical factor evaluation system of customized production project.

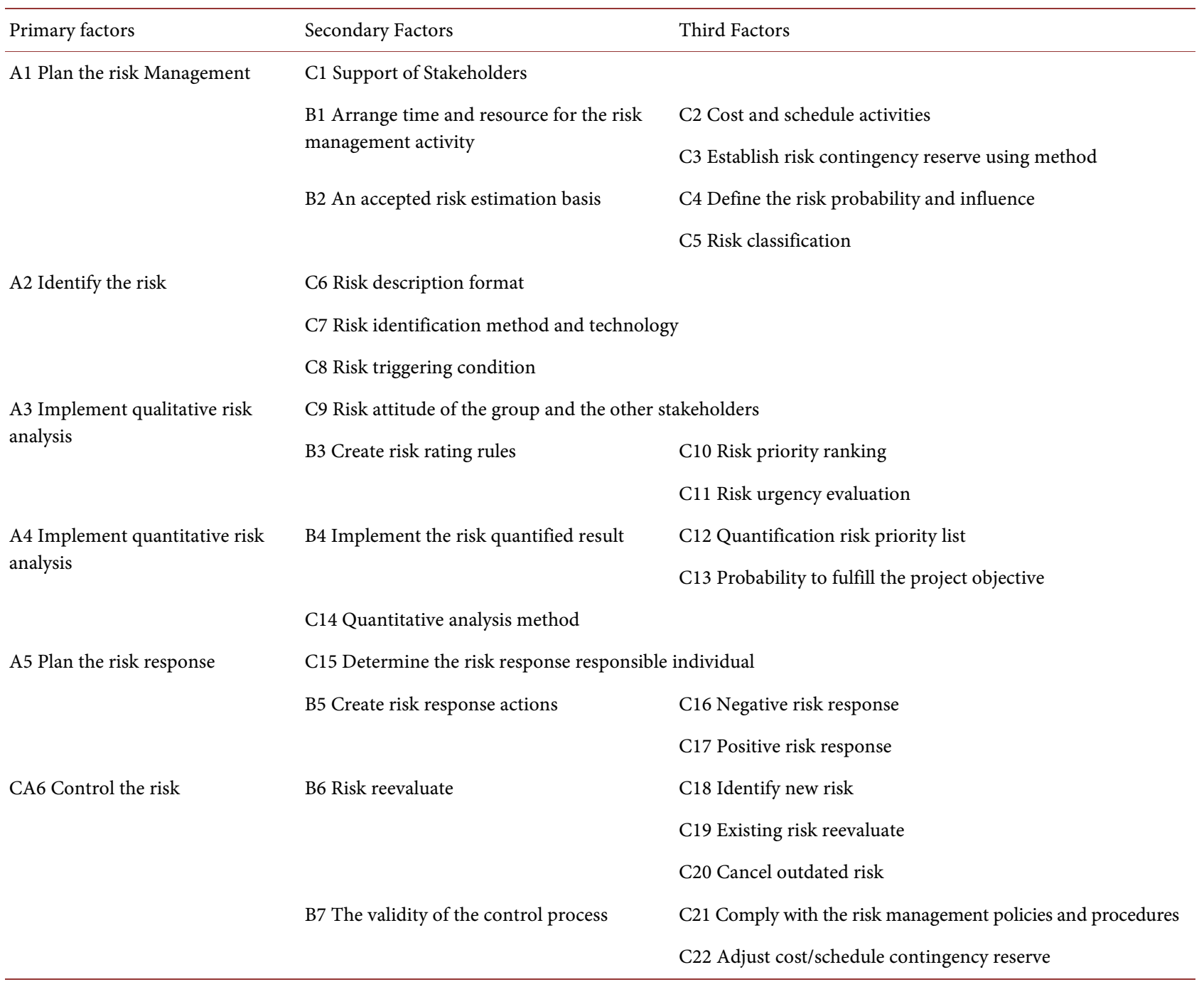


3) Check consistency

4) Calculate the final weight value.

\subsection{Create Hierarchy Structure Model}

In order to create hierarchy structure model, we need to define the target layer, standard layer and decision layer. The target of this paper is to find out the critical factor of customized production project, so the target layer is effective risk management (A). Because the paper is based on the PMBOK risk management, so the 6 processes (plan the risk management, identify the risk, implement qualitative risk analysis, implement quantitative risk analysis, plan the risk response and control the risk) are the standard layer (B1-B6). At last, we use the 22 risk factors from Delphi as the decision layer (C1-C22). See below Figure 1.

\subsection{Construct Comparison Matrix}

In order to construct comparison matrix for AHP, we need to compare the importance of each factor in the same group. According to the interview information with the industry experts, we get the comparison value. We compare the factor $i$ with the factor $j$ in the same group, and mark them from 1 to 9.1 means factor $i$ is as important as factor $j, 3$ means factor $i$ is a little more important than factor $j, 5$ means factor $i$ is obviously more important than factor $j, 7$ means factor $i$ is intensely more important than factor $j, 9$ means factor $i$ is extremely more important than factor $j$, the other number means the importance is between its

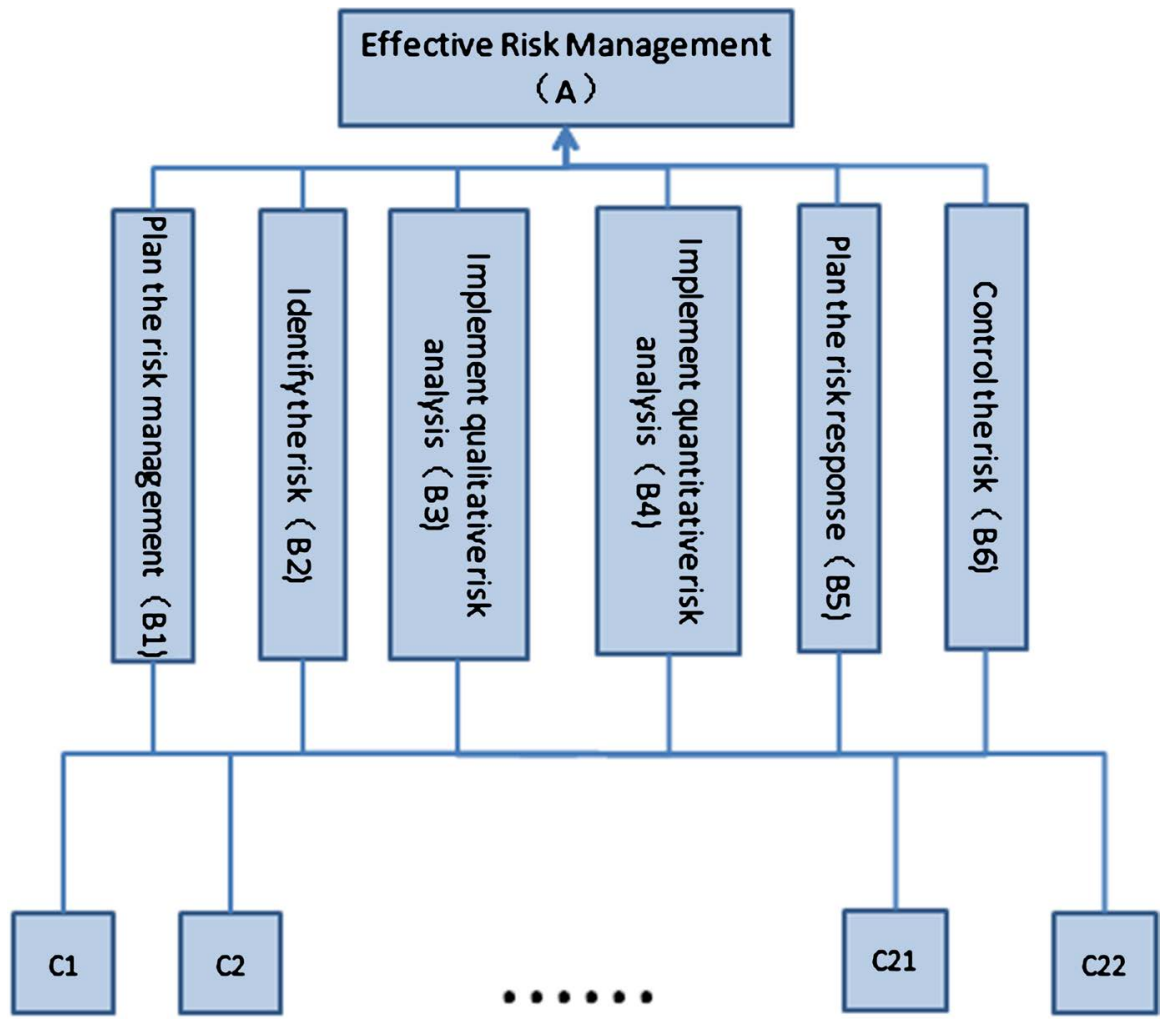

Figure 1. Hierarchy structure model. 
front number and the latter number. The importance of $j$ to $i$ is the reciprocal of the importance of $i$ to $j$. See Table 2 for the definition of each scale number.

After summarized all the information, we get the below comparison matrix: Table 3 is the comparison matrix between decision layer $\mathrm{C} 1$ to $\mathrm{C} 5$ of the standard layer B1; Table 4 is the comparison matrix between decision layer C6 to C8 of the standard layer B2; Table 5 is the comparison matrix between decision layer C9 to C11 of the standard layer B3; Table 6 is the comparison matrix between decision layer $\mathrm{C} 12$ to $\mathrm{C} 14$ of the standard layer B4; Table 7 is the comparison matrix between decision layer $\mathrm{C} 15$ to $\mathrm{C} 17$ of the standard layer B5; Table 8 is the comparison matrix between decision layer $\mathrm{C} 18$ to $\mathrm{C} 22$ of the standard layer B6; Table 9 is the comparison matrix between standard layer B1 to B6 of

Table 2. Definition of each scale number for the comparison matrix.

\begin{tabular}{cc} 
Scale aij & Definition \\
\hline 1 & factor $i$ is as important as factor $j$ \\
5 & factor $i$ is a little more important than factor $j$ \\
7 & factor i i is intensely more important than factor $j$ \\
9 & factor $i$ is extremely more important than factor $j$ \\
$2,4,6,8$ & the importance is between its front number and the latter number \\
reciprocal & When compare $j$ to $i$, the aji $=1 /$ aij
\end{tabular}

Table 3. Decision layer comparison matrix of standard layer B1.

\begin{tabular}{cccccc}
\hline & $\mathrm{C} 1$ & $\mathrm{C} 2$ & $\mathrm{C} 3$ & $\mathrm{C} 4$ & $\mathrm{C} 5$ \\
\hline $\mathrm{C} 1$ & 1 & 7 & 5 & 5 & 3 \\
$\mathrm{C} 2$ & $1 / 7$ & 1 & $1 / 3$ & $1 / 2$ & $1 / 3$ \\
$\mathrm{C} 3$ & $1 / 5$ & 3 & 1 & 3 & 3 \\
$\mathrm{C} 4$ & $1 / 5$ & 2 & $1 / 3$ & 1 & $1 / 3$ \\
$\mathrm{C} 5$ & $1 / 3$ & 3 & $1 / 3$ & 3 & 1 \\
\hline
\end{tabular}

Table 4. Decision layer comparison matrix of standard layer B2.

\begin{tabular}{cccc}
\hline & C6 & C7 & C8 \\
\hline C6 & 1 & $1 / 3$ & $1 / 7$ \\
C7 & 3 & 1 & $1 / 5$ \\
C8 & 7 & 5 & 1 \\
\hline
\end{tabular}

Table 5. Decision Layer Comparison Matrix of Standard Layer B3.

\begin{tabular}{cccc}
\hline & C9 & C10 & C11 \\
\hline C9 & 1 & $1 / 5$ & $1 / 3$ \\
C10 & 5 & 1 & 3 \\
C11 & 3 & $1 / 3$ & 1 \\
\hline
\end{tabular}


Table 6. Decision layer comparison matrix of standard layer B4.

\begin{tabular}{cccc}
\hline & $\mathrm{C} 12$ & $\mathrm{C} 13$ & $\mathrm{C} 14$ \\
\hline $\mathrm{C} 12$ & 1 & 3 & 5 \\
$\mathrm{C} 13$ & $1 / 3$ & 1 & 3 \\
$\mathrm{C} 14$ & $1 / 5$ & $1 / 3$ & 1 \\
\hline
\end{tabular}

Table 7. Decision layer comparison matrix of standard layer B5.

\begin{tabular}{cccc}
\hline & $\mathrm{C} 15$ & $\mathrm{C} 16$ & $\mathrm{C} 17$ \\
\hline $\mathrm{C} 15$ & 1 & 3 & 5 \\
$\mathrm{C} 16$ & $1 / 3$ & 1 & 3 \\
$\mathrm{C} 17$ & $1 / 5$ & $1 / 3$ & 1 \\
\hline
\end{tabular}

Table 8. Decision layer comparison matrix of standard layer B6.

\begin{tabular}{cccccc}
\hline & C18 & C19 & C20 & C21 & C22 \\
\hline C18 & 1 & 3 & 7 & $1 / 3$ & 5 \\
C19 & $1 / 3$ & 1 & 5 & $1 / 5$ & 3 \\
$\mathrm{C} 20$ & $1 / 7$ & $1 / 5$ & 1 & $1 / 7$ & $1 / 3$ \\
$\mathrm{C} 21$ & 3 & 5 & 7 & 1 & 5 \\
$\mathrm{C} 22$ & $1 / 5$ & $1 / 3$ & 3 & $1 / 5$ & 1 \\
\hline
\end{tabular}

Table 9. Standard layer comparison matrix of target layer A.

\begin{tabular}{ccccccc}
\hline & B1 & B2 & B3 & B4 & B5 & B6 \\
\hline B1 & 1 & $1 / 3$ & 3 & 5 & $1 / 3$ & $1 / 5$ \\
B2 & 3 & 1 & 3 & 5 & $1 / 3$ & $1 / 5$ \\
B3 & $1 / 3$ & $1 / 3$ & 1 & 3 & $1 / 5$ & $1 / 7$ \\
B4 & $1 / 5$ & $1 / 5$ & $1 / 3$ & 1 & $1 / 7$ & $1 / 9$ \\
B5 & 3 & 3 & 5 & 7 & 1 & $1 / 3$ \\
B6 & 5 & 5 & 7 & 9 & 3 & 1 \\
\hline
\end{tabular}

the target layer A.

After we get the comparison matrix, we calculate the relative weight $\mathrm{Wi}$ of factor $\mathrm{i}$ to the upper layer. The formula for Wi as below:

$$
W i=Q i / Q a \text {, and } Q i=\left(\prod_{j=1}^{n} C i j\right)^{\frac{1}{n}}, C i j \text { is the importance scale of factor i to }
$$
factor $j$.

$$
Q a=/(i, j=1,2, \cdots n)
$$

This paper use YAAHP to run the AHP calculation. Table 10 to Table 16 are the relative weight result of all the factors. 
Table 10. Relative weight result of target layer A.

\begin{tabular}{|c|c|c|c|c|c|c|c|}
\hline \multicolumn{8}{|c|}{ Effective risk management consistency ratio of the judgment matrix: 0.0028 ; the weight to the target: $1.0000 ; \lambda_{\max }: 6.0179$} \\
\hline effective risk management & $\begin{array}{l}\text { Plan the } \\
\text { risk management }\end{array}$ & $\begin{array}{l}\text { Identify } \\
\text { the risk }\end{array}$ & $\begin{array}{l}\text { Implement qualitative } \\
\text { risk analysis }\end{array}$ & $\begin{array}{c}\text { Implement quantitative } \\
\text { risk analysis }\end{array}$ & $\begin{array}{l}\text { Plan the } \\
\text { risk response }\end{array}$ & $\begin{array}{l}\text { Control } \\
\text { the risk }\end{array}$ & $\mathrm{Wi}$ \\
\hline Plan the risk management & 1 & 0.6703 & 1.4918 & 2.2255 & 0.6703 & 0.4493 & 0.1367 \\
\hline Identify the risk & 1.4918 & 1 & 1.4918 & 2.2255 & 0.6703 & 0.4493 & 0.1562 \\
\hline Implement qualitative risk analysis & 0.6703 & 0.6703 & 1 & 1.4918 & 0.4493 & 0.3012 & 0.098 \\
\hline Implement quantitative risk analysis & 0.4493 & 0.4493 & 0.6703 & 1 & 0.3012 & 0.2019 & 0.0657 \\
\hline Plan the risk response & 1.4918 & 1.4918 & 2.2255 & 3.3201 & 1 & 0.6703 & 0.2181 \\
\hline Control the risk & 2.2255 & 2.2255 & 3.3201 & 4.953 & 1.4918 & 1 & 0.3253 \\
\hline
\end{tabular}

Table 11. Relative weight result of standard layer B1.

\section{Plan the risk management consistency ratio of the judgment matrix:0.0126; the weight to the target:0.1367; $\lambda_{\max }: 5.0563$}

\begin{tabular}{lcccccc}
\hline \multicolumn{1}{c}{ Plan the risk management } & $\begin{array}{c}\text { C1 Support } \\
\text { of Stakeholders }\end{array}$ & $\begin{array}{c}\text { C2 Cost and } \\
\text { schedule } \\
\text { activities }\end{array}$ & $\begin{array}{c}\text { C3 Establish } \\
\text { risk contingency } \\
\text { reserve using method }\end{array}$ & $\begin{array}{c}\text { C4 Define the risk } \\
\text { probability and } \\
\text { influence }\end{array}$ & $\begin{array}{c}\text { C5 Risk } \\
\text { classification }\end{array}$ Wi \\
C1 Support of Stakeholders & 1 & 3.3201 & 2.2255 & 2.2255 & 1.4918 & 0.3525 \\
C2 Cost and schedule activities & 0.3012 & 1 & 0.6703 & 0.8187 & 0.6703 & 0.1197 \\
C3 Establish risk contingency reserve using method & 0.4493 & 1.4918 & 1 & 1.4918 & 1.4918 & 0.2014 \\
C4 Define the risk probability and influence & 0.4493 & 1.2214 & 0.6703 & 1 & 0.6703 & 0.1405 \\
C5 Risk classification & 0.6703 & 1.4918 & 0.6703 & 1.4918 & 1 & 0.1859 \\
\hline
\end{tabular}

Table 12. Relative weight result of standard layer B2.

\begin{tabular}{|c|c|c|c|c|}
\hline \multicolumn{5}{|c|}{ Identify the risk consistency ratio of the judgment matrix: 0.0000 ; the weight to the target: $0.1562 ; \lambda_{\max }: 3.0000$} \\
\hline Identify the risk & $\begin{array}{c}\text { C6 Risk } \\
\text { description format }\end{array}$ & $\begin{array}{l}\text { C7 Risk identification } \\
\text { method and technology }\end{array}$ & $\begin{array}{l}\text { C8 Risk triggering } \\
\text { condition }\end{array}$ & Wi \\
\hline C6 Risk description format & 1 & 0.6703 & 0.3012 & 0.1721 \\
\hline C7 Risk identification method and technology & 1.4918 & 1 & 0.4493 & 0.2567 \\
\hline C8 Risk triggering condition & 3.3201 & 2.2255 & 1 & 0.5713 \\
\hline
\end{tabular}

Table 13. Relative weight result of standard layer B3.

Implement qualitative risk analysis consistency ratio of the judgment matrix:0.0000; the weight to the target:0.0980; $\lambda_{\max }: 3.0000$

\begin{tabular}{lcccc}
\hline \multicolumn{1}{c}{ Implement qualitative risk analysis } & $\begin{array}{c}\text { C9 Risk attitude of the group } \\
\text { and the other stakeholders }\end{array}$ & $\begin{array}{c}\text { C10 Risk } \\
\text { priority ranking }\end{array}$ & $\begin{array}{c}\text { C11 Risk } \\
\text { urgency evaluation }\end{array}$ & Wi \\
\hline C9 Risk attitude of the group and the other stakeholders & 1 & 0.4493 & 0.6703 & 0.212 \\
C10 Risk priority ranking & 2.2255 & 1 & 1.4918 & 0.4718 \\
C11 Risk urgency evaluation & 1.4918 & 0.6703 & 1 & 0.3162 \\
\hline
\end{tabular}


Table 14. Relative weight result of standard layer B4.

\begin{tabular}{lcccc}
\hline \multicolumn{1}{c}{ Implement quantitative risk analysis consistency ratio of the judgment matrix: $\mathbf{0 . 0 0 0 0}$; the weight to the target: $0.0657 ; \lambda_{\max }: 3.0000$} \\
\hline \multicolumn{1}{c}{ Implement quantitative risk analysis } & $\begin{array}{c}\text { C12 Quantification } \\
\text { risk priority list }\end{array}$ & $\begin{array}{c}\text { C13 Probability to fulfill } \\
\text { the project objective }\end{array}$ & $\begin{array}{c}\text { C14 Quantitative } \\
\text { analysis method }\end{array}$ & Wi \\
\hline C12 Quantification risk priority list & 1 & 1.4918 & 2.2255 & 0.4718 \\
C13 Probability to fulfill the project objective & 0.6703 & 1 & 1.4918 & 0.3162 \\
C14 Quantitative analysis method & 0.4493 & 0.6703 & 1 \\
\hline
\end{tabular}

Table 15. Relative weight result of standard layer B5.

\begin{tabular}{lcccc}
\hline \multicolumn{4}{c}{ Plan the risk response consistency ratio of the judgment matrix: $\mathbf{0 . 0 0 0 0}$; the weight to the target: $\mathbf{0 . 2 1 8 1 ;} \boldsymbol{\lambda}_{\max }: \mathbf{3 . 0 0 0 0}$} \\
\hline \multicolumn{1}{c}{ Plan the risk response } & $\begin{array}{c}\text { C15 Determine the risk response } \\
\text { responsible individual }\end{array}$ & $\begin{array}{c}\text { C16 Negative } \\
\text { risk response }\end{array}$ & $\begin{array}{c}\text { C17 Positive } \\
\text { risk response }\end{array}$ & Wi \\
\hline C15 Determine the risk response responsible individual & 1 & 1.4918 & 2.2255 & 0.4718 \\
C16 Negative risk response & 0.6703 & 1 & 1.4918 & 0.3162 \\
C17 Positive risk response & 0.4493 & 0.6703 & 1 & 0.212 \\
\hline
\end{tabular}

Table 16. Relative weight result of standard layer B6.

\begin{tabular}{|c|c|c|c|c|c|c|}
\hline \multicolumn{7}{|c|}{ Control the risk consistency ratio of the judgment matrix: 0.0057 ; the weight to the target: $0.3253 ; \lambda_{\max }: 5.0256$} \\
\hline Control the risk & $\begin{array}{c}\mathrm{C} 18 \\
\text { Identify } \\
\text { new risk }\end{array}$ & $\begin{array}{l}\text { C19 Existing } \\
\text { risk } \\
\text { reevaluate }\end{array}$ & $\begin{array}{l}\text { C20 Cancel } \\
\text { outdated } \\
\text { risk }\end{array}$ & $\begin{array}{l}\text { C21 Comply with the risk } \\
\text { management policies and } \\
\text { procedures }\end{array}$ & $\begin{array}{c}\text { C22 Adjust } \\
\text { cost/schedule } \\
\text { contingency reserve }\end{array}$ & Wi \\
\hline C18 Identify new risk & 1 & 1.4918 & 3.3201 & 0.6703 & 2.2255 & 0.2663 \\
\hline C19 Existing risk reevaluate & 0.6703 & 1 & 2.2255 & 0.4493 & 1.4918 & 0.1785 \\
\hline C20 Cancel outdated risk & 0.3012 & 0.4493 & 1 & 0.3012 & 0.6703 & 0.0869 \\
\hline $\begin{array}{l}\text { C21 Comply with the risk management } \\
\text { policies and procedures }\end{array}$ & 1.4918 & 2.2255 & 3.3201 & 1 & 2.2255 & 0.3386 \\
\hline C22 Adjust cost/schedule contingency reserve & 0.4493 & 0.6703 & 1.4918 & 0.4493 & 1 & 0.1296 \\
\hline
\end{tabular}

\subsection{Check Consistency}

After we calculate the weight of each factor, we need to check the consistency of the comparison matrix. Calculate the consistency ratio $\mathrm{CR}$ of each matrix. If the CR is less than 0.1, it's acceptable. Otherwise, we need to rerun the comparison matrix. We can get the CR from the below formula.

$$
C R=\frac{C I}{R I}, C I=\left(\lambda_{\max }-n\right) /(n-1),
$$

The RI can be found from Table 17 based on the latitude $\mathrm{n}$ (the quantity of factors).

$$
\lambda_{\max }=\sum_{i=1}^{n} \frac{(A Q) i}{n \times Q i},
$$

$(A Q) i$ is the product of a row matrix and a column matrix. Row matrix is the row $i$ of the comparison matrix, column matrix is the relative weight matrix of the comparison matrix. Qi is from the relative weight calculation in chapter 4.3. 
We can get the CR of each comparison matrix from Table 10 to Table 16 and they are all less than 0.1 , which is acceptable to the consistency check. Table 18 is the summary of all the CR.

\subsection{Calculate the Final Weight Value}

Multiply the relative weight of each factor by the relative weight of corresponding standard layer. We can get the final weight of all the 22 factors, rank them in descending order, we get the below final weight list of all the factors, Table 19.

Table 17. Random consistency index value of RI.

\begin{tabular}{cccccccccc}
\hline $\mathrm{n}$ & 1 & 2 & 3 & 4 & 5 & 6 & 7 & 8 & 9 \\
\hline $\mathrm{RI}$ & 0 & 0 & 0.58 & 0.90 & 1.12 & 1.28 & 1.32 & 1.41 & 1.45 \\
\hline
\end{tabular}

Table 18. CR value of the comparison matrix.

\begin{tabular}{cccccccc}
\hline & B1 & B2 & B3 & B4 & B5 & B6 & A \\
\hline CR & 0.0126 & 0.0000 & 0.0000 & 0.0000 & 0.0000 & 0.0057 & 0.0028 \\
\hline
\end{tabular}

Table 19. Final weight list of all the factors.

\begin{tabular}{llc}
\hline \multicolumn{1}{c}{ factor } & weight & ranking \\
\hline C21 Comply with the risk management policies and procedures & 0.1101 & 1 \\
C15 Determine the risk response responsible individual & 0.1029 & 2 \\
C8 Risk triggering condition & 0.0893 & 3 \\
C18 Identify new risk & 0.0866 & 4 \\
C16 Negative risk response & 0.069 & 5 \\
C19 Existing risk reevaluate & 0.0581 & 6 \\
C1 Support of Stakeholders & 0.0482 & 7 \\
C10 Risk priority ranking & 0.0462 & 8 \\
C17 Positive risk response & 0.0462 & 9 \\
C22 Adjust cost/schedule contingency reserve & 0.0422 & 10 \\
C7 Risk identification method and technology & 0.0401 & 11 \\
C11 Risk urgency evaluation & 0.031 & 12 \\
C12 Quantification risk priority list & 0.031 & 13 \\
C20 Cancel outdated risk & 0.0283 & 14 \\
C3 Establish risk contingency reserve using method & 0.0275 & 15 \\
C6 Risk description format & 0.0269 & 16 \\
C5 Risk classification & 0.0254 & 17 \\
C9 Risk attitude of the group and the other stakeholders & 0.0208 & 18 \\
C13 Probability to fulfill the project objective & 0.0208 & 19 \\
C4 Define the risk probability and influence & 0.0192 & 20 \\
C2 Cost and schedule activities & 0.0164 & 21 \\
C14 Quantitative analysis method & 0.0139 & 22 \\
\hline & & 79 \\
\hline
\end{tabular}


With the AHP, we can calculate the weight value of all the 22 factors. Ranking them in descending order, we can get top 10 factors as the risk management critical factors. AHP combines the qualitative and quantitative analysis, the project manager can find out the critical factors quickly. It's very helpful to analysis and solves problems during project management.

\section{Management Enlightenment}

Top 10 critical factors belong to Plan the risk management, Identify the risk, Implement qualitative risk analysis, Plan the risk response and Control the risk. Besides, Plan the risk response and Control the risk are particularly important, they include 7 of 10 critical factors. Project manager can pay extra attention to them.

The weight value of top two factors is obviously bigger. Comply with the risk management policies and procedures as the NO.1 critical factor means it's very important to ensure the risk management policies and procedures are well executed and complied during the whole risk management cycle. Only in this way we can provide theoretical basis to the other risk management activities. Besides, we should determine the responsible individual for each risk, only when the responsible individual take his own responsibility, follow the risk management policies and procedures, the risk can be well managed.

According to the top 10 critical factors, we can identify the top 10 risks. For example, No.3 critical factor is Risk triggering condition. The corresponding risk is the structure failure. When the product is manufactured, it's very difficult to tell whether there is a structure issue. But the customers are the professional players. They are much stronger and faster than the amateurs which means the sticks will be broken after several shoots. And broken sticks in the professional level will affect the brand reputation. In order to manage this risk, we should take actions in advance to describe the triggering condition of the structure failure.

As we can see from the final weight list of the factors, the weight of the last five factors are much lower. Which means it will not have too much influence to the whole project. So we don't need to spend too much resource on them. Just need to review them in a certain period.

\section{Conclusion}

In this paper, based on the six processes of risk management, we identify the critical factors of customized production projects with Delphi. We get 7 secondary factors and 22 third factors from original 6 primary factors, and establish the critical factor evaluation system of customized production project. Then we calculate the weight of all the factors from critical factor evaluation system with AHP. After ranking them in descending order, we get top 10 critical factors. They are C21, C15, C8, C18, C16, C19, C1, C10, C17 and C22. With the top 10 critical factors list, project manager can manager each factor specifically, which 
will improve the efficiency of project management.

\section{Acknowledgements}

Thanks a lot for your valuable guidance, Professor Jiangping Wan.

\section{Conflicts of Interest}

The authors declare no conflicts of interest regarding the publication of this paper.

\section{References}

[1] Jeffrey, L. (2017) 14 Management Principles from the World's Greatest Manufacturer. Li, F.L. Translated. China Machine Press.

[2] Yan, F.H., Dang, X. and Yan, W.H. (2007) Summary of Risk Management Progress and Trend. Management Modernization, No. 2, 30-33.

[3] Zhang, Q. and Chen, L.Q. (2008) Summary of Risk Management Theory Follow and the Latest Study Trend. Financial Theory \& Practice, No. 10, 105-109.

[4] Rodriguez, E. and Edwards, J.S. (2009) Knowledge Management and Enterprise Risk Management Implementation in Financial Services. Society of Actuaries, No. 12.

[5] Xu, J.L. and Zhou, J.X. (1998) Risk Management. China Finance Publishing House, Beijing.

[6] Qi, A.B. (2010) Project Risk Management. Nankai University Press, Tianjin, 1-35.

[7] Project Management Institute. (2013) Project Management Body of Knowledge (PMBOK Guide). 5th Edition, Publishing House of Electronics Industry, Beijing, 309-312.

[8] Song, Z.H. and Ma, Q.M. (2012) Excel on the Application of Establishing Evaluation Index System with AHP. Statistics and Decision, No. 21, 104-105. 